\title{
INFLUENCE OF MATRIX DIFFUSION AND ADSORPTION ON RADIONUCLIDE TRANSPORT
}

Chunhong Li

Duke Engineering \& Services

1650 University Blvd., NE.

Suite 300

Albuquerque, NM 87102

(505)-848-0852

\author{
Jim E. Houseworth \\ Duke Engineering \& Services \\ 1180 Town Center Drive \\ Las Vegas, Nevada 89134 \\ (702)-295-4638
}

\author{
Bruce A. Robinson \\ EES-5 \\ Los Alamos National Laboratory \\ Los Alamos, NM 87545 \\ (505)-667-1910
}

\section{INTRODUCTION}

Two important factors that affect radionuclide transport in fractured rock media are matrix diffusion and matrix adsorption. Studies both in saturated and unsaturated zones have shown that matrix diffusion and matrix adsorption can play a key role in retarding the movement of solutes in fractured porous media. The influence of matrix diffusion and matrix adsorption is important for the system performance analyses of the potential high level radioactive waste repository at Yucca Mountain. In our study, we focus on radionuclide transport in unsaturated fractured media. Factors that affect the strength of matrix diffusion and matrix adsorption are matrix diffusion coefficients, radionuclide residence time in fractures, matrix adsorption coefficients, and the relative magnitudes of fracture and matrix flow fractions. Among them, the largest uncertainty is the flow distribution between fractures and matrix in the system and how it is going to affect the strength of matrix diffusion and matrix adsorption. In this paper, we carry out simulations with different fracture and matrix flow configurations to address the importance of flow configurations on matrix diffusion and matrix adsorption.

\section{NUMERICAL SIMULATIONS}

A two dimensional east-west cross section (Robinson ${ }^{[1]}$ et al., 1997) that cut through the proposed repository was used in the simulations. There are 4 rock units in the profile: welded Tiva Canyon (TCw), nonwelded Paintbrush (PTn), welded Topopah Spring (TSw), and nonwelded Calico Hills and Prow Pass formations with vitric and zeolitic layers $(\mathrm{CHn})$. The welded and zeolitic rocks, TCw, TSw, and zeolitic layers of $\mathrm{CHn}$, are characterized by low matrix permeabilities on the order of microdarcies, while the nonwelded rocks, PTn and vitric layers of the $\mathrm{CHn}$, are characterized by much higher permeabilities on the order of millidarcies.
Two sets of hydrological parameters for the fracture/ matrix system were used to develop two different flow configurations in the field. The first parameter set (set 1) is from Bodvarsson ${ }^{[2]}$ et al., (1997) Table 6.4.-1-2 with fracture-matrix contact area reduction factors introduced to reflect fingering flow in unsaturated fractures. The reduction factors vary from layer to layer with the lowest values in the welded units (on the order of $1.0 \mathrm{E}-4$ in $\mathrm{TCW}$ and most layers of TSw) and highest values in the nonwelded units (around 0.5 in the PTn and $\mathrm{CHn}$ ). The second parameter set (set 2) is from Robinson ${ }^{[3]}$ et al., (1995). Compared to set 1 , set 2 has a slightly lower fracture permeability $\left(6.0 \mathrm{E}-10 \mathrm{~m}^{2}\right.$ vs. $2.0 \mathrm{E}-9 \mathrm{~m}^{2}$ for set 1$)$ in CHn and relative lower matrix permeabilities in $\mathrm{CHn}$ zeolitic layers (7.E-18 $\mathrm{m}^{2}$ vs. $9.12 \mathrm{E}-18$ to $5.75 \mathrm{E}-17 \mathrm{~m}^{2}$ for set 1 ), higher fracture van Genuchten $n$ parameters for all layers (3 vs. 1.97 for set 1 ), and no fracture-matrix contact area reduction factors. Application of these two parameter sets in the radionuclide transport simulations generated two different flow configurations in the Calico Hills unit: dominated fracture flow for parameter set 1; dominated matrix flow for parameter set 2 . This difference in flow configurations resulted in substantially different effects of matrix diffusion and matrix adsorption on radionuclide transport.

\section{SIMULATION RESULTS}

We applied the Finite Element Heat and Mass transfer code (FEHM, Zyvoloski[4] et al., 1995) with dual permeability and particle tracking options to simulate radionuclide transport in the unsaturated zone below the repository. An average infiltration rate of $4.0 \mathrm{~mm} /$ year was applied at the top of the mountain. Radionuclide transport simulations were performed for neptunium (Np). A total of 100,000 particles representing $152.1 \mathrm{mols}$ of $\mathrm{Np}$ at the repository were released at a constant rate from 0 to 5,000 
years. Four cases were investigated: no matrix diffusion or matrix adsorption, matrix diffusion $\left(D_{m}=1.0 \mathrm{E}-11 \mathrm{~m}^{2} / \mathrm{s}\right)$ but no matrix adsorption, matrix adsorption $\left(\mathrm{K}_{\mathrm{d}}=2.5 \mathrm{cc} / \mathrm{g}\right.$ in the Calico Hills zeolitic layers) but no matrix diffusion, and finally matrix diffusion and adsorption $\left(D_{m}=1.0 \mathrm{E}-11 \mathrm{~m}^{2} / \mathrm{s}\right.$ and $K_{d}=2.5 \mathrm{cc} / \mathrm{g}$ in the Calico Hills zeolitic layers). All four cases were run using parameter sets 1 and 2, respectively.

The mass flow rate curves for the two parameter sets under different conditions are plotted in Figures 1 and 2, respectively. Figure 1 shows that for fracture dominated flow, the radionuclides travel at faster speed and arrive at the bottom of $\mathrm{UZ}$ at higher concentrations than those in Figure 2. This is due to the short residence time of radionuclides in fractures and less fracture to matrix flow. The effect of matrix diffusion and matrix adsorption on radionuclide transport is minimal. Matrix adsorption alone has no effect on radionuclides travelling in fractures. Figure 2 represents the transport process of radionuclides in a system with matrix dominated flow and strong flow exchanges between fractures and matrix. As for the case in Figure 1, matrix diffusion only plays a minor role in reducing the amount of radionuclides carried in fractures, and matrix adsorption alone has no effect on radionuclide transport through fractures but can greatly reduces the peak and retard the travel time of radionuclides moving through matrix. Compared to the mass flow rate curves from set 1 , the combined effects of matrix diffusion and matrix adsorption in this case is much more prominent, which is reflected by the large reduction in the peak mass flow rate and the retardation of the peak arrival time. Such strong effects of matrix diffusion and matrix adsorption is determined by the relative low fractional fracture flow in the system. Figure 1 and 2 both show that the effect of matrix diffusion is reversible. Matrix diffusion can move the adsorbed radionuclides back into the fractures, so at some time follow the fracture mass flow rate peak, the mass flow rate curves from the combined effects are higher than those just by matrix adsorption.

\section{CONCLUSIONS}

The simulation results from our study indicate that in unsaturated fractured media with fracture dominated flow, matrix diffusion and matrix adsorption only have limited effects on radionuclide transport in the system. On the other hand, in a system dominated by matrix flow, matrix diffusion and matrix adsorption can significantly reduce the peak mass flow rate and retard the movement of radionuclides. When matrix adsorption is present, matrix diffusion plays an important role in enhancing fracturematrix interactions and retarding the radionuclide transport process in fractures.

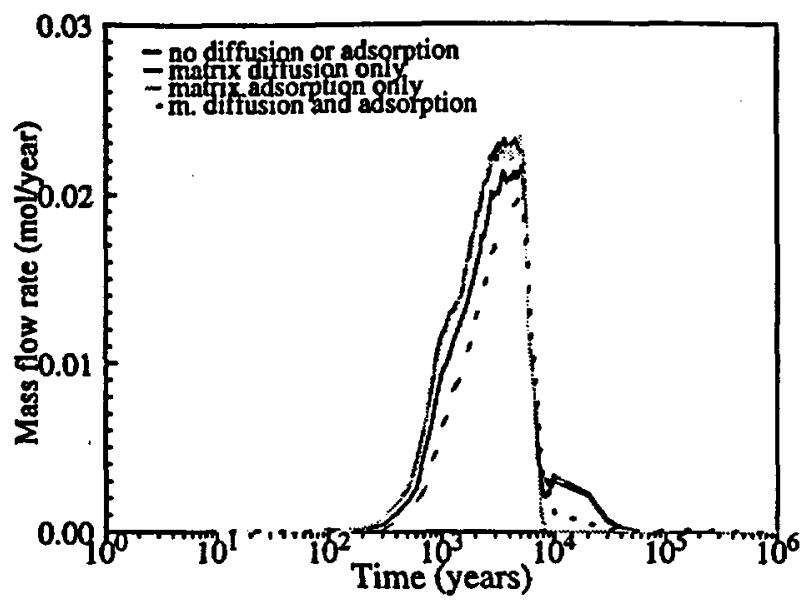

Figure 1. Mass flow rate curves of parameter set 1.

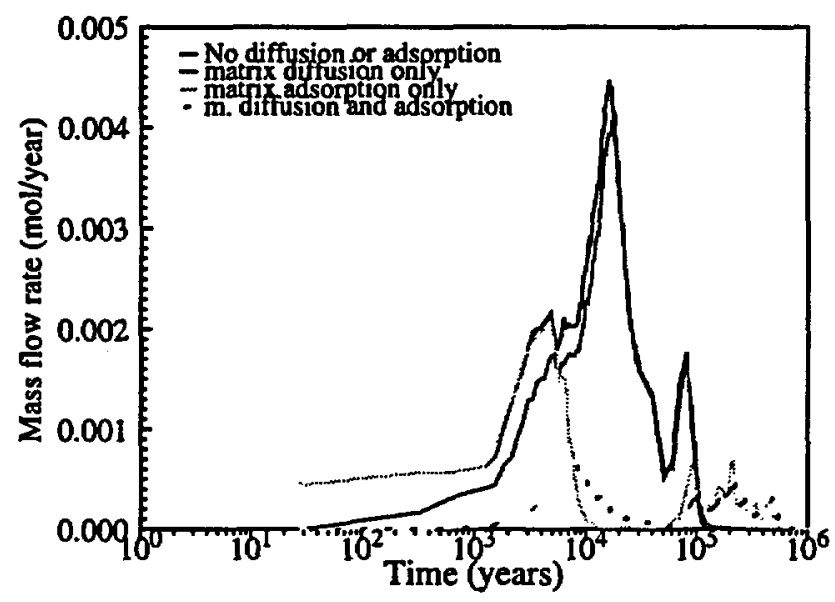

Figure 2. Mass flow rate curves of parameter set 2.

\section{ACKNOWLEDGMENTS}

This work was supported by Yucca Mountain Site Characterization Office, part of the US Department of Energy's Radioactive Waste Management Program.

\section{REFERENCES}

1. Robinson, B.A., A.V. Wolfsberg, H.S. Viswanathan, G.Y. Bussod, C.W. Gable, and A. Meijer, The site-scale unsaturated zone transport model of Yucca Mountain, Milestone SP25BM3, Los Alamos National Laboratory, 1997.

2. Bodvarsson, G.S., T.M. Bandurraga, and Y.S. Wu, The site-scale unsaturated zone model of Yucca Mountain, 
Nevada, for the viability Assessment. Technical Report LBNL-40378, Lawrence Berkeley National Laboratory, 1997.

3. Robinson, B.A., A.V. Wolfsberg, G.A. Zyvoloski, and C.W. Gable, An unsaturated zone flow and transport model of Yucca Mountain, Los Alamos National Laboratory YMP Milestone, 3468, 1995.

4. Zyvoloski, A.G., B.A. Robinson, Z.A. Dash, and L.L. Trease, Models and methods summary for the FEHMN application, Technical Report LA-UR-94-3787, Rev. 1, Los Alamos National Laboratory, $1995 \mathrm{~b}$. 